\title{
Analysis of interregional cooperation based on commodity exchange development trends
}

\author{
Liudmila Borisova ${ }^{1, *}$ and Dina Borisova ${ }^{2}$ \\ ${ }^{1}$ Don State Technical University, sq. Gagarina, 1, 344003 Rostov-on-Don, Russia
}

\begin{abstract}
The study presents the results obtained on the basis of the application of the instrumental-mathematical apparatus for modeling socioeconomic processes and systems, including the economic integration of regions, which in further research can be the basis for developing scenarios for the development of interregional ties. The article proposes an approach based on modeling the process of interregional economic integration using the tools of correlation and regression analysis. The results of applying the methodology for aligning the time series of changes in commodity exchange in value terms using the example of the regions of the Southern Federal District made it possible to determine the parameters of the regression line and to check their significance. The presented analysis of the graphical dependences of the commodity exchange of the Rostov region with the rest of the regions characterizes the degree of development and trends of interregional economic integration.
\end{abstract}

\section{Introduction}

To search for and find rational and effective solutions to deepen interregional cooperation, an objective assessment of the existing level, potential and limitations of the interregional cooperation process is required. To assess the state and prospects for the development of interregional economic cooperation (along with its other types: production and technological, information and communication, etc.), the priority is to analyze the development trends of interregional trade as a carrier of integration and economic functions.

Currently, approaches based on the use of the instrumental and mathematical apparatus for the analysis of interregional cooperation are used, but they have not been sufficiently worked out yet [1-9]

In particular, in [2], the study is based on the use of methods of structural and functional analysis and is predominantly descriptive. In [3], existing knowledge is synthesized, a conceptual framework for the analysis of interregional flows is developed, and the impact of flows of ecosystem services on interregional sustainability is considered. A small number of works are devoted to the issues of mathematical modeling of the process of interregional economic cooperation [4]. At the same time, this problem is urgent.

\footnotetext{
* Corresponding author: borisovalv09@mail.ru
} 
The aim of the study is to obtain new results in assessing interregional economic cooperation based on the use of correlation and regression analysis.

\section{Methodology}

Analysis of a priori information and existing research methods for interregional cooperation indicates the need to create an instrumental and mathematical apparatus for quantitatively assessing interregional integration, combining various methodological approaches into a single integral system of methods that takes into account both the quantitative and qualitative nature of the information and analytical base of interregional economic cooperation, including statistical methods for studying the dynamics of cross-border trade in the regions of the Southern Federal District [10-12]. The data of the Federal State Statistics Service of the Russian Federation, regional statistical bodies and other information sources were used as empirical material.

One of the traditional mathematical methods in the study of interregional economic cooperation and the dynamics of cross-border commodity exchange of regions involves its quantitative assessment based on the methods of correlation and regression analysis [13]. These types of analysis include checking the presence of a correlation, its direction, checking the significance of the correlation coefficients, building a regression model $y=f\left(x_{1}, x_{2}, \ldots x_{n}\right)$ the investigated relationship between the indicator $y$ and factors $\mathrm{x}$. To characterize the intensity of changes in features over time, various indicators of time series are used. Studying the dynamics of a socio-economic phenomenon involves testing the null hypothesis of a trend; if available, construction of the trend equation and further extrapolation of the results.

The Southern Federal District as a large socio-economic system includes: Rostov Region, Krasnodar Territory, Astrakhan and Volgograd Regions, Adygea and the Republic of Kalmykia.

It was previously established that interregional integration is based on economic interest and is regulated by a system of socio-economic laws and legal norms. Any interregional relationships are implemented through various types of activities in the following areas: innovation, investment, information, resource, energy, production and technological cooperation, scientific and technical cooperation, financial interaction, exchange of natural and labor resources.

The process of economic unification of regional entities on the basis of improving deep stable relationships and further development of the social division of labor underlies the understanding of the subject content of the category of economic integration.

The effectiveness of interactions at various levels of the hierarchical structure of the economic system depends on the tools for managing such processes. By regulating these relationships, it is necessary to strive to achieve an optimal balance of economic interests of all parties involved, to ensure consistency of actions, focusing on the use of competitive advantages, consistency and predictability of expected results.

The motivational interest in this case lies in the mutual benefit from this kind of cooperation, in which the integration processes are effective in the case of joint activities of regions as a result of the unification of their economies.

The territorial proximity of the cooperating regions gives positive success to the interregional dynamics due to the reduction of transport costs.

Moreover, the proximity of territories is a relative concept. On the one hand, it makes it possible to reduce transaction costs and helps to eliminate administrative barriers. On the other hand, integration is also possible in the presence of territorial remoteness of regions 
from each other. This option is effective in the development of trade relations.

The degree of development of energy and transport and logistics infrastructures decisively contributes to the intensity of interregional integration and determines the structure and volume of interregional trade [14].

Providing interregional economic systems with the requirements of openness, cooperativity and dynamism associated with the variability of the two main characteristics of the market - supply and demand, allows them to be classified as self-organizing systems.

"Economic growth, taking into account the dynamic development of interregional ties, depends on several factors:

- the spatial and territorial location of the region, taking into account trade, economic and financial flows;

- the degree of development of the transport and logistics infrastructure: the state of aviation, sea, river, rail, highways serving trade and economic interactions;

- the degree of availability of logistics centers and warehouses of wholesale trade".

From this position, the results of the functioning of interregional markets can be divided into the following categories: - goods and services of a strategic nature related to ensuring the country's security; - goods and services produced in the region from the standpoint of technological rationality; - goods and services produced for the independent consumption of the region within the framework of its economic space.

The existing criteria for ranking economic entities of the national economy are associated with assessing the impact of their level of development on the processes of spatial development of the Russian economy. As a result, underdeveloped, depressed and developed regions can be distinguished [15].

Underdeveloped regions are characterized by: insufficient intensity of economic processes, low living standards of the population and structured economy, as a result of which they lag behind other regions in terms of production and technical level of development. These regions today include about 25 constituent entities of the Russian Federation (including the constituent entities of the Southern Federal District: the Republic of Adygea, the Republic of Kalmykia).

The depressed regions include about 30 constituent entities, these are the regions that, despite the sufficient production and technical potential, a significant share of industry in the region and the presence of a highly qualified workforce, are in a state of depression. Consequently, we can note here a low investment activity, a lack of innovative activity, affecting, among other things, the degree of employment of the population (structural unemployment).

The developed regions act as a kind of donors to the economy. Among them are industrial, agricultural and raw materials. They act as poles of activity and economic growth and entail other regions through the "diffusion of innovations". These are about 15 regions, which are the flagships of economic processes.

Overcoming the same interregional imbalances and asymmetries requires a constant search for adequate and effective tools to eliminate them.

The process of interregional redistribution of resources is rather limited and cannot, in full measure, provide support for lagging regions. However, the problem of smoothing out socio-economic differences between regions remains quite urgent.

The conditions for the effectiveness of interregional integration can be identified:

- demand for this form of interaction by partner parties;

- unity of geoeconomic and geopolitical interests of the subjects;

- relative equality of levels of socio-economic development;

- territorial proximity of the participants in the integration process. 
As a result of the qualitative analysis, the effects of the development of interregional integration were revealed, expressed in synergy and an increase in target indicators of the socio-economic development of the national economy, such as the level of well-being of the population and the quality of life, the level of development of the transport and logistics infrastructure, the level of employment, the level of investment attractiveness, etc. business activity, the level of sustainable development of regions, the level of environmentally friendly living conditions of the population of the regions.

Integration is based, first of all, on the sufficient proximity of the regions according to the principles of the formation of the economic mechanism, production and technical base and the nature of reproduction processes, according to the degree of use of an approximately homogeneous labor force and according to the readiness of regions for integration.

The presence of significant differences between regions leads to the difficulty of integration processes or to a decrease in their effect. In this case, economic relations will be limited to the sphere of trade, episodic movements of capital, goods or labor.

Thus, interregional integration acts as a driver of socio-economic development and contributes to an increase in the standard of living of the population of the regions and the country as a whole. Regions should form a common economic complex based on the principle of complementarity. This is what will contribute to the widespread development of interregional integration.

For the long-term development of this process, a number of factors are required that determine the level of the existing production and transport and logistics base, which should become the foundation of integration cooperation. When assessing the transport and logistics features and the level of transport links of partner regions, it is necessary to take into account the following elements among the conditions for interregional integration: the presence of sea and river ports, airports, the density of railway communications per 10,000 km2; length of railway tracks, km; commodity exchange, million tons; density of paved roads per 1000 $\mathrm{km}^{2}$, etc. The state of the level of development of communications, as one of the modules of interregional integration, must be assessed by such quantitative indicators as the number of connected subscriber devices of mobile radiotelephone communication per 1000 people, pcs; the number of points of collective access (PCA) with access to the Internet; number of active subscribers of fixed broadband Internet access, thousand; - the number of active subscribers of mobile radiotelephone communication using Internet access services, thousand, etc. "

Integration is based, first of all, on the basis of a sufficient proximity of regions in terms of the level of development of their economies, according to the principles of the formation of an economic mechanism, production and technical base and the nature of reproduction processes, according to the degree of use of an approximately homogeneous labor force and according to the readiness of regions for integration.

Within the framework of this study, the production function is cross-border trade, which is characterized by the import/export of products, as well as the volume of trade in three large types of products: food purposes (FP); non-food purposes (NFP); industrial and technical purpose (ITP) of the Rostov region with the regions of the Southern Federal District.

\section{Results}

To study the commodity exchange, as the most important indicator of interregional interaction and the degree of development of economic ties, statistical data of time series were analyzed characterizing the total commodity exchange of the Rostov region with each of the regions of the Southern Federal District for 2009-2019 (fig.1-fig.5). 
The use of the tools of correlation-regression analysis made it possible to determine the parameters of the regression line and to check their significance.

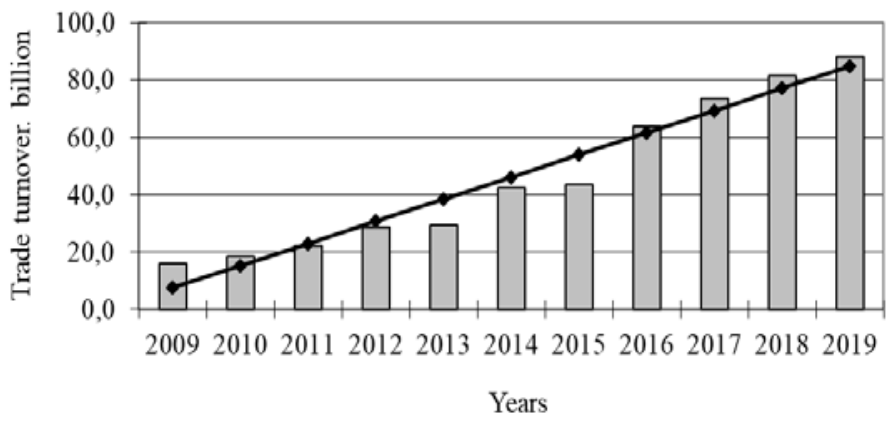

Fig. 1. Dynamics of the total commodity exchange of the Rostov Region with the Krasnodar Territory (regression equation $y=-15541+7,74 \times x ; \mathrm{r}^{2}=0.95$ )

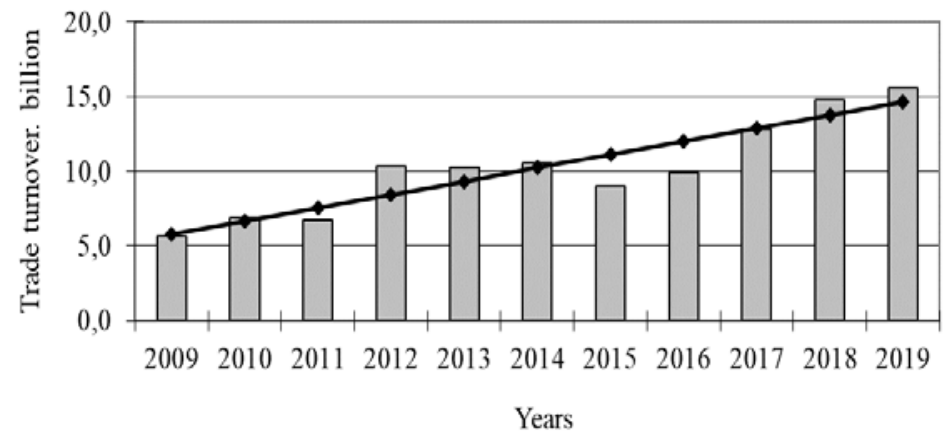

Fig. 2. Dynamics of the total commodity exchange of the Rostov region with the Astrakhan region (regression equation $y=-1778,1+0,89 \times x ; \mathrm{r}^{2}=0.84$ )

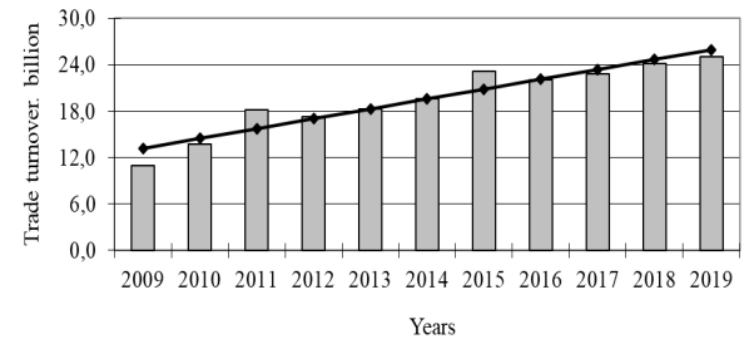

Fig. 3. Dynamics of the total commodity exchange of the Rostov region with the Volgograd region (regression equation $y=-2548,7+1,28 \times x ; \mathrm{r}^{2}=0.91$ ) 


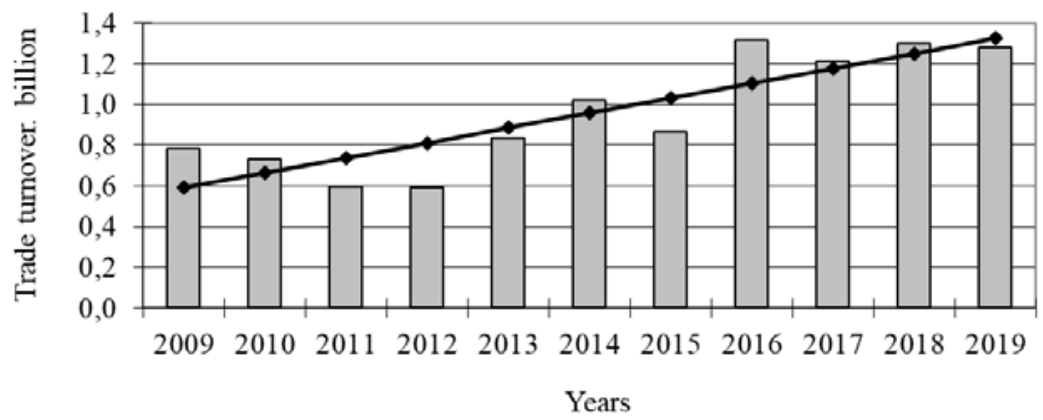

Fig. 4. Dynamics of the total commodity exchange of the Rostov region with the Republic of Adygea (regression equation $y=-146,65+0,073 \times x \quad \mathrm{r}^{2}=0,76$ )

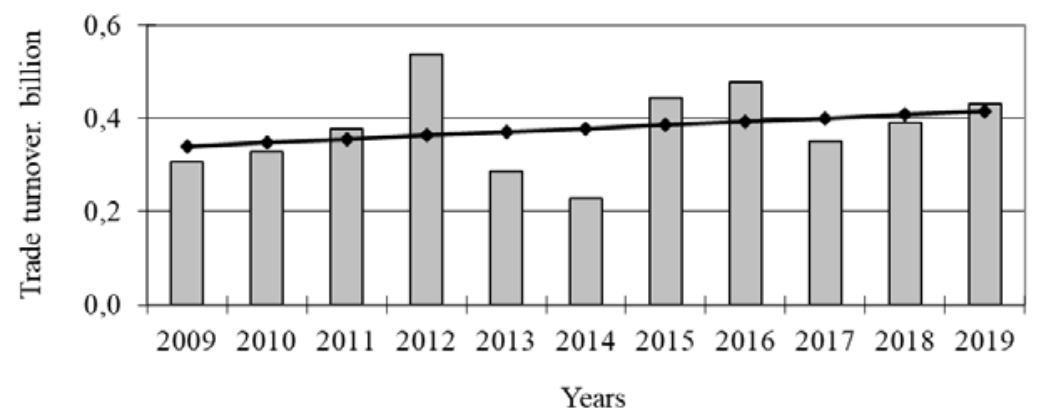

Fig. 5. Dynamics of the total commodity exchange of the Rostov region with the Republic of Kalmykia (regression equation $y=-14,62+0,0075 \times x \mathrm{r}^{2}=0,07$ )

Thus, the analysis of the presented graphical dependencies indicates a significant increase in the commodity exchange of the RR with the regions of the Southern Federal District, which is a sign of the development of interregional economic integration.

\section{Conclusion}

The scientific results obtained as a result of the application of the modernized instrumental and mathematical apparatus for modeling socio-economic processes and systems, including the economic integration of regions, the results of correlation and regression analysis, which are the basis for the development of scenarios for the development of interregional ties, information management decision-making support systems, which in aggregate can be used by regional government bodies to strengthen interregional economic ties, develop integration processes between regions of the country.

\section{References}

1. L. Bozhko Development scenarios for the interregional economic interaction in the context of economy clustering in the Republic of Kazakhstan. Energy Procedia 147, 397 401 (2018) doi.org/10.1016/j.egypro.2018.07.109 
2. M. Schröter, T. Koellner, R. Alkemade, S. Arnhold, K. J. Bagstad, K.-H. Erb, K. Frank, T. Kastner, M. Kissinger, J. Liu, L. López-Hoffman, J. Maes, A. Marques, B. MartínLópez, C. Meyer, C. J.E.Schulp, J. Thober, S. Wolff, A. Bonn Interregional flows of ecosystem services: Concepts, typology and four cases. Ecosystem Services 31(B), 231241 (2018) https://doi.org/10.1016/j.ecoser.2018.02.003

3. E.N. Zakharova, E.E. Kardava, R.R. Avanesova, E.P. Avramenko, Management of the economic capacity of the region on the basis of foresight (on the example of Adygea, Russia). Regional Science Inquiry 8(2), 45-54 (2016)

4. V.V. Prokhorova, E.N. Zakharova, Peculiarities of corporate governance methodology. Journal of Internet Banking and Commerce 21(S4), 010 (2016)

5. E.N. Tishchenko, T.N. Sharypova, E.V. Zhilina, S.E. Cherkezov, Economic and mathematical modeling of complex cooperation of academic staff of educational cluster on the basis of fuzzy sets theory. Journal of Applied Economic Sciences 11(5), 905-907 (2016)

6. E.N. Tishchenko, P.P. Belenkiy, T.N. Sharypova, O.V. Serpeninov, Methods of organization of protected data processing center of virtual economic object. International Journal of Applied Engineering Research 11(5), 3066-3074 (2016)

7. K.A. Butsik, E.N. Tishchenko, A mathematical model of a trusted download violator process «hardware thin client». CEUR Workshop Proceedings. YSIP2 2017 Proceedings of the 2nd Young Scientist's International Workshop on Trends in Information Processing, 32-37 (2017)

8. N.G. Vovchenko, M.B. Gontmacher, E.N. Tishchenko, T.V. Epifanova, Electronic currency: the potential risks to national security and methods to minimize them. European Research Studies Journal 20(1), 36-48 (2017)

9. E.N. Tishchenko, E.V. Zhilina, T.N. Sharypova, G.N. Palyutina, Fuzzy models of the results of the mastering the educational programs in the field of information security. Advances in Intelligent Systems and Computing 896, 694-701 (2019) doi.org/10.1007/978-3-030-04164-9_91

10. D.V. Borisova, G.V. Gorelova, Cognitive instrumentarium for interregional economic integration investigation. International scientific journal «Stable development of mountain areas» 11(1), 65-7 - 0,7/0,4 p.s. (2019)

11. D.V. Borisova, Cognitive modelling of interregional economic integration in terms of fuzzy data. Cognitive modelling: Proceedings of the Seventh International forum on cognitive modelling (5 - 15 September 2019, Retimno, Greece, i. Crete). In 3 parts. Part 3. Cognitive modelling in science, culture, education: Proceedings of VII International conference "Cognitive modelling in science, culture, education. CMSCE-2019», $243-$ 252 (Rostov-on-Don: Science and Education Fund, 2019)

12. D.V. Borisova, G.V. Gorelova, N.D. Pankratova, Problems of interregional integration, cognitive modeling. 19th IFAC Conference on Technology, Culture and International Stability TECIS 2019 Sozopol, Bulgaria, 26-28 September, 168-173 (2019) doi.org/10.1016/j.ifacol.2019.12.467

13. Y. Jiang, Interregional disparity and the development of inland regions. Trade, Foreign Direct Investment, and Development Strategies Chandos Asian Studies Series, 75-98 (2014) doi.org/10.1533/9781780634432.75

14. A. Landysh, T. Gadelshina, M. Vakhitova, The Place and Role of Transport Infrastructure in the Interregional Integration of the Russian Federation Regions 
Procedia Economics and Finance 24, 246-250 (2015) doi.org/10.1016/S22125671(15)00655-3

15. T. F. Remington, Why is interregional inequality in Russia and China not falling? Communist and Post-Communist Studies 48(1), 1-13 (2015) doi.org/10.1016/j.postcomstud.2015.01.005 